\title{
Age-Related Clinical Outcomes of Patients with Non-Valvular Atrial Fibrillation: Insights from the COOL-AF Registry
}

\section{Rungroj Krittayaphong' \\ Thanita Boonyapiphat ${ }^{2}$ Chaiyasith Wongvipaporn ${ }^{3}$ Poom Sairat' \\ On behalf of the COOL-AF Investigators}

'Division of Cardiology, Department of Medicine, Faculty of Medicine Siriraj Hospital, Mahidol University, Bangkok, Thailand; ${ }^{2}$ Division of Cardiology, Department of Medicine, Lampang Hospital, Lampang, Thailand; ${ }^{3}$ Division of Cardiology, Department of Medicine, Srinakarind Hospital, Faculty of Medicine, Khon Kaen University, Khon Kaen, Thailand
Correspondence: Rungroj Krittayaphong Division of Cardiology, Department of Medicine, Faculty of Medicine Siriraj Hospital, Mahidol University, 2 Wanglang Road, Bangkoknoi, Bangkok, 10700, Thailand

Tel +66 2-419-6104

Fax +66 2-4I2-74I2

Email rungroj.kri@mahidol.ac.th
Purpose: We aimed to compare the rate of clinical outcomes among three age groups $(<65$, $65-74$, and $\geq 75$ years) of adult patients with non-valvular atrial fibrillation (NVAF).

Patients and Methods: We prospectively enrolled NVAF patients from 27 Thailand medical centers. The following were collected at baseline: demographic data, risk factors, comorbid conditions, laboratory data, and medications. The clinical outcomes were ischemic stroke (IS) or transient ischemic attack (TIA), major bleeding (MB), intracerebral hemorrhage (ICH), heart failure (HF), and death. All events were adjudicated. Patients were categorized according to age group into three groups; age $<65,65-74$, and $\geq 75$ years.

Results: Among the 3402 patients that were enrolled during 2014-2017, the mean age was 67.4 \pm 11.3 years, and $2073(60.9 \%)$ were older. The average follow-up was $25.7 \pm 10.6$ months. Oral anticoagulants were given in $75.4 \%$ of patients ( $91.1 \%$ of OAC was warfarin). The incidence rate of IS/TIA, MB, ICH, HF, and death was 1.43 (1.17-1.74), 2.11 (1.79-2.48), 0.70 (0.52-0.92), 3.03 (2.64-3.46), and 3.77 (3.33-4.24) per 100 person-years, respectively. The risk of IS/TIA, $\mathrm{MB}, \mathrm{ICH}, \mathrm{HF}$, and death increased with age both before and after adjustment for potential confounders. Even though OAC reduced the risk of IS/TIA, it increased the risk of MB. Net clinical benefit $(\mathrm{NCB})$ analysis favored oral anticoagulant (OAC) in the high-risk subset of older adults.

Conclusion: Older adult NVAF patients had a significantly increased risk of IS/TIA, MB, $\mathrm{ICH}, \mathrm{HF}$, and death compared to younger NVAF before and after adjustment for potential confounders. Strategies to reduce overall risk, including OAC use and choice and integrated care, should be implemented.

Keywords: age-related clinical outcomes, patients, non-valvular atrial fibrillation, NVAF, COOL-AF registry, Thailand

\section{Introduction}

Non-valvular atrial fibrillation (NVAF) is the most common sustained cardiac arrhythmia. ${ }^{1}$ The prevalence of NVAF is approximately $1 \%$; however, it is more commonly found in older adults with a prevalence of up to $10 \%{ }^{1}$ Ischemic stroke is one of the most common devastating complications of $\mathrm{NVAF}^{2}{ }^{2}$ The risk of ischemic stroke was approximately 5 times higher in patients with NVAF compared to those without. ${ }^{2}$ The $\mathrm{CHA}_{2} \mathrm{DS}_{2}$-VASc scoring system is the standard tool used for assessing the risk of ischemic stroke in patients with NVAF. ${ }^{2}$ Age greater than 75 years is given 2 points in the $\mathrm{CHA}_{2} \mathrm{DS}_{2}$-VASc scoring system, whereas age between 65 and 75 is given 1 point. ${ }^{3}$ Therefore, the majority of older adults with NVAF require 
oral anticoagulant (OAC) for stroke prevention. ${ }^{4-6}$ The risk of major bleeding also increased in older adult NVAF, especially when they are on OAC. ${ }^{7-9}$ The bleeding site of most concern is intracerebral hemorrhage (ICH), which occurred in approximately $0.3-0.7 \%$ of the patients who received warfarin. ${ }^{10}$ Asian population had a higher rate of ICH compared to Western population. ${ }^{11}$ Despite the increased risk of bleeding among the elderly, OAC is still indicated since the benefit of stroke prevention outweighs the risk of major bleeding. ${ }^{12}$ The overall use of OAC in Asian population is lower than in Western population ${ }^{13}$ due to a fear of major bleeding. ${ }^{14}$ Although non-vitamin $\mathrm{K}$ antagonist oral anticoagulant (NOAC) had a lower rate of $\mathrm{ICH}$, warfarin remains the most commonly used OAC in many Asian countries due to its comparatively lower cost. ${ }^{15}$ Previous study showed that the quality of international normalized ratio (INR) is poor in Asian population. $^{13}$

The aim of this study was to compare the incidence rate of clinical outcomes among three age groups $(<65$, $65-74$, and $\geq 75$ years) of adult patients with non-valvular atrial fibrillation (NVAF) with NVAF using prospective data from a nationwide NVAF registry in Thailand.

\section{Patients and Methods}

\section{Study Population}

We studied patients from the COhort of antithrombotic use and Optimal INR Level in patients with non-valvular Atrial Fibrillation in Thailand (COOL-AF) registry, which is a prospective registry of subjects with NVAF from 27 hospitals in Thailand. All subjects were enrolled during 2014-2017. The registry information was described in the previous publication. ${ }^{15}$ This is a nationwide registry of patients with non-valvular atrial fibrillation. The purpose of the registry was to study the antithrombotic pattern and optimal INR level for those who were on warfarin. All data were recorded in the web-based system. Investigators were informed to enroll consecutive cases. Site monitoring was performed to ensure data quality. The study population comprised patients with atrial fibrillation confirmed by electrocardiography (ECG) who were 18 years or older. Patients having one or more of the following were excluded: 1) thrombocytopenia or myeloproliferative disorders; 2) recent onset of ischemic stroke within 3 months; 3) atrial fibrillation from reversible or transient cause; 4) prosthetic heart valve; 5) rheumatic valve disease; 6) inability to attend follow-up visits; 7) pregnancy; 8) unwillingness to participate; 9) disease with life expectancy less than 3 years; and/or 10) current participation in an ongoing clinical trial. This study was approved by the Institutional Review Board of each participating hospital, and all patients provided written informed consent prior to participation.

\section{Study Protocol}

Site investigators and study nurses were instructed to enroll patients consecutively. Baseline data were recorded from data in the medical record and from patient interview. All data were noted in the case record form (CRF) with subsequent entry into our registry's web-based system. All CRFs were sent to the registry's data management unit for verification. A query was sent to the study site if any question(s) arose during the verification process. Data during follow-up were recorded every 6 months until 3 years.

\section{Data Collection}

Baseline patient characteristics were recorded, which included demographic data, cardiovascular risk factors, vital signs, physical examination data, medications, laboratory (including kidney function) or investigation data, and the components of the $\mathrm{CHA}_{2} \mathrm{DS}_{2}$-VASc and HAS-BLED scores. Anatomical Therapeutic Chemical Classification (ATC) codes for warfarin, dabigatran, rivaroxaban, apixaban, and edoxaban were B01AA03, $\mathrm{B} 01 \mathrm{AE} 07, \mathrm{~B} 01 \mathrm{AF} 01, \mathrm{~B} 01 \mathrm{AF} 02$, and $\mathrm{B} 01$, respectively. Clinical outcomes during follow-up were recorded. Only patients who had at least 6 months of follow-up data were included in this study.

\section{Outcomes}

The main outcome measurements were ischemic stroke or transient ischemic attack (TIA), major bleeding, ICH, heart failure, and death. Documents relating to clinical outcome were uploaded into the web-based system Outcome data were confirmed by the adjudication committee.

\section{Definitions}

Hypertension: systolic blood pressure $140 \mathrm{mmHg}$, or diastolic blood pressure $90 \mathrm{mmHg}$ at least 2 visits, or being treated with antihypertensive medication. Diabetes mellitus: fasting plasma glucose at least $126 \mathrm{mg} / \mathrm{dl}$ at least twice, $\mathrm{HbA} 1 \mathrm{C}$ at least $6.5 \%$, or random plasma glucose at least $200 \mathrm{mg} / \mathrm{dl}$, or being treated with antihyperglycemic 
medication. Smoking: current smoker (smoke at least one cigarette per day at least 1 month, stop less than 3 months), or ex-smoker (smoking at least one cigarette per day at least 1 month, stop more than 3 months). Dyslipidemia: at least one of the following; total cholesterol (TC) $>200 \mathrm{mg} / \mathrm{dL}(5.18 \mathrm{mmol} / \mathrm{L}), \mathrm{LDL}-\mathrm{C}>130 \mathrm{mg} /$ $\mathrm{dL}(3.37 \mathrm{mmol} / \mathrm{L}), \mathrm{HDL}-\mathrm{C}<40 \mathrm{mg} / \mathrm{dL}(1.04 \mathrm{mmol} / \mathrm{L})$ or TG $>150 \mathrm{mg} / \mathrm{dL}$. Dementia: diagnosis of dementia or Alzheimer's disease in the medical record, not include mild cognitive impairment Heart failure: documented hospital admission with heart failure as the primary diagnosis. Coronary artery disease: positive stress test for myocardial ischemia or imaging study (coronary CT angiography or coronary angiography), history of documented myocardial infarction, or myocardial revascularization.

\section{Definition of Outcomes}

Ischemic stroke or TIA: acute onset of focal neurological deficit lasting more than 24 hours for ischemic stroke, and less than 24 hours for TIA. Whether positive or negative, imaging data from computerized tomography (CT) brain scan or magnetic resonance imaging (MRI) were required to be uploaded into the web-based system.

Major bleeding: International Society of Thrombosis and Haemostasis (ISTH) criteria. $^{16}$

\section{Statistical Analysis}

Descriptive data were reported as mean and standard deviation (SD) for continuous data, and number and percentage for categorical data. Student $t$-test for unpaired data was used to compare two groups of continuous data, whereas chi-square test was used to compare categorical data. Univariate and multivariate analysis using Cox proportional hazard function was performed to identify independent predictors of clinical outcomes. Those results were reported as hazard ratio (HR) and adjusted HR along with their respective $95 \%$ confidence intervals (CIs). Log rank test was used to compare the findings of Kaplan-Meier analysis between groups. Patients were categorized according to age group into 3 groups; age $<65,65-74$, and $\geq 75$ years. $R$ graph was used to display the HR of clinical events when treating age as a continuous variable. A $p$-value was considered significant when it was less than 0.05 . The net clinical benefit (NCB) of using OAC versus no OAC, and warfarin versus NOACs was performed using the following formula: (ischemic stroke/TIA rate ${ }_{\text {off }} \mathrm{OAC}$ - ischemic stroke/TIA rate $\left._{\text {on } \mathrm{OAC}}\right)-1.5\left(\mathrm{ICH}\right.$ rate $_{\text {on } \mathrm{OAC}}-\mathrm{ICH}$ rate $\left._{\text {off }} \mathrm{OAC}\right) .{ }^{17}$
NCB was performed for the whole group as well as for the high-risk group which was defined as those with $\mathrm{CHA}_{2}$ $\mathrm{DS}_{2}$-VASc score $\geq 2$ for male and $\geq 3$ for female. Statistical analysis was performed using SPSS version 18.0 (SPSS, Inc., Chicago, IL, USA), and $\mathrm{R}$ program version 3.6.5 from the R Project for Statistical Computing.

\section{Results}

\section{Baseline Clinical Characteristics}

A total of 3402 patients were enrolled. The mean age was $67.4 \pm 11.3$ years, and $58.2 \%$ were male. The proportion of adults with age $<65,65-74$, and $\geq 75$ years was 1329 (39.1\%), 1094 (32.1\%), and 979 (28.8\%) patients, respectively. Baseline characteristics are shown in Table 1 . The older adult group had a higher rate of permanent atrial fibrillation, history of coronary artery disease (CAD), use of cardiac electronic implantable devices (CIED), history of ischemic stroke/TIA, hypertension, dyslipidemia, dementia, history of bleeding, higher $\mathrm{CHA}_{2} \mathrm{DS}_{2}$-VASc and HAS-BLED score, and anticoagulant use, and a lower rate of symptomatic atrial fibrillation and smoking compared to the younger adult group.

\section{Clinical Outcomes}

The average follow-up duration was $25.7 \pm 10.6$ months The incidence rate of ischemic stroke/TIA, major bleeding, ICH, heart failure, and death was 1.43 (1.17-1.74), 2.11 (1.79-2.48), 0.70 (0.52-0.92), 3.03 (2.64-3.46), and $3.77(3.33-4.24)$ per 100 person-years, respectively. Figure 1 shows the incidence rate of clinical outcomes compared between 3 age groups $(<65,65-74$, and $\geq 75$ years). All types of events increased with age. Table 2 shows number of each clinical event and incidence rate per 100 person-years of patients with age $<65,65-74$, and $\geq 75$ years. The incidence rates of ischemic stroke/TIA of the three age groups according to $\mathrm{CHA}_{2} \mathrm{DS}_{2}$-VASc score are shown in Table 3.

Univariate and multivariate analysis was performed to assess the effect of age on the rate of clinical outcomes after adjustment for potential confounders, including baseline clinical data, comorbid conditions, and medications, including OAC. Univariate Cox proportional Hazard model was performed for each outcome using all variables listed in Table 1. Variables with a p-value $<0.2$ from univariate analysis were selected for multivariate Coxproportional Hazard model analysis. Age group was forced into all multivariate models. Our results revealed older 
Table I Baseline Characteristics of All Patients, and Compared Between Patients Aged <65, 65-74 and $\geq 75$ Years

\begin{tabular}{|c|c|c|c|c|c|}
\hline Variables & All $(N=3402)$ & Age $<65(n=1329)$ & Age 65-74 $(n=1094)$ & Age $\geq 75(n=979)$ & p-value \\
\hline Age (years) & $67.4 \pm 11.3$ & $56.10 \pm 7.14$ & $69.49 \pm 2.89$ & $80.32 \pm 4.24$ & $<0.001^{a, b, c}$ \\
\hline Female gender & $1422(4 \mid .8 \%)$ & $463(34.8 \%)$ & $469(42.9 \%)$ & $490(50.1 \%)$ & $<\left.0.00\right|^{a, b, c}$ \\
\hline Time after diagnosis of AF (years) & $3.36 \pm 4.325$ & $2.79 \pm 3.43$ & $3.74 \pm 4.8 \mathrm{I}$ & $3.70 \pm 4.75$ & $<0.001^{\mathrm{a}, \mathrm{b}}$ \\
\hline Atrial fibrillation & & & & & $0.00 I^{b}$ \\
\hline - Paroxysmal & II 48 (33.7\%) & $490(36.9 \%)$ & $371(33.9 \%)$ & $287(29.3 \%)$ & \\
\hline - Persistent & $643(18.9 \%)$ & $257(19.3 \%)$ & $205(18.7 \%)$ & I8I (I8.5\%) & \\
\hline - Permanent & $161 \mid(47.4 \%)$ & $582(43.8 \%)$ & $518(47.3 \%)$ & $5 \mathrm{II}(52.2 \%)$ & \\
\hline Symptomatic AF & $2618(77.0 \%)$ & $1065(80.1 \%)$ & 824 (75.3\%) & 729 (74.5\%) & $0.002^{a, b}$ \\
\hline History of heart failure & $912(26.8 \%)$ & $378(28.4 \%)$ & $278(25.4 \%)$ & $256(26.1 \%)$ & 0.211 \\
\hline History of coronary artery disease & $547(16.1 \%)$ & $161(12.1 \%)$ & 205 (18.7\%) & 181 (18.5\%) & $<0.00 I^{\mathrm{a}, \mathrm{b}}$ \\
\hline Cardiac implantable electronic device & $34 I(10.0 \%)$ & $76(5.7 \%)$ & $120(11.0 \%)$ & 145 (14.8\%) & $<\left.0.00\right|^{a, b, c}$ \\
\hline History of ischemic stroke/TIA & $592(17.4 \%)$ & 189 (14.2\%) & $187(17.1 \%)$ & $216(22.1 \%)$ & $<0.00 I^{\mathrm{a}, \mathrm{c}}$ \\
\hline Hypertension & $2328(68.4 \%)$ & $759(57.1 \%)$ & $792(72.4 \%)$ & 777 (79.4\%) & $<\left.0.00\right|^{a, b, c}$ \\
\hline Diabetes mellitus & $839(24.7 \%)$ & $316(23.8 \%)$ & $298(27.2 \%)$ & $225(23.0 \%)$ & $0.05 \mathrm{I}$ \\
\hline Smoking & $678(19.9 \%)$ & $298(22.4 \%)$ & $220(20.1 \%)$ & $160(16.3 \%)$ & $0.00 I^{b}$ \\
\hline Dyslipidemia & 1915 (56.3\%) & 661 (49.7\%) & $679(62.1 \%)$ & $575(58.7 \%)$ & $<0.00 I^{\mathrm{a}, \mathrm{b}}$ \\
\hline Renal replacement therapy & $40(1.2 \%)$ & $14(1.1 \%)$ & $17(1.6 \%)$ & $9(0.9 \%)$ & 0.355 \\
\hline Dementia & $29(0.9 \%)$ & $6(0.5 \%)$ & $8(0.7 \%)$ & $15(1.5 \%)$ & $0.018^{b}$ \\
\hline CKD & $205 \mathrm{I}(60.3 \%)$ & $510(38.4 \%)$ & 726 (66.4\%) & 815 (83.2\%) & $<0.001^{a, b, c}$ \\
\hline History of bleeding & $323(9.5 \%)$ & $90(6.8 \%)$ & $113(10.3 \%)$ & $120(12.3 \%)$ & $<0.00 I^{\mathrm{a}, \mathrm{b}}$ \\
\hline $\mathrm{CHA}_{2} \mathrm{DS}_{2}$-VASc score & & & & & $<0.001^{a}$ \\
\hline-0 & $196(5.8 \%)$ & $196(14.7 \%)$ & $0(0.0 \%)$ & $0(0.0 \%)$ & \\
\hline-1 & $422(12.4 \%)$ & $371(27.9 \%)$ & $51(4.7 \%)$ & $0(0.0 \%)$ & \\
\hline$-\geq 2$ & 2784 (8I.8\%) & 762 (57.3\%) & $1043(95.3 \%)$ & 979 (100.0\%) & \\
\hline HAS-BLED score & & & & & $<0.00 \mathrm{I}^{\mathrm{a}}$ \\
\hline-0 & 490 (14.4\%) & 484 (36.4\%) & $6(0.5 \%)$ & $0(0.0 \%)$ & \\
\hline$-1-2$ & $2373(69.8 \%)$ & $798(60.0 \%)$ & 839 (76.7\%) & 736 (75.2\%) & \\
\hline$-\geq 3$ & 539 (15.8\%) & 47 (3.5\%) & $249(22.8 \%)$ & $243(24.8 \%)$ & \\
\hline Antiplatelet & 890 (26.2\%) & $366(27.5 \%)$ & $293(26.8 \%)$ & 231 (23.6\%) & 0.088 \\
\hline Anticoagulant & $2566(75.4 \%)$ & $880(66.2 \%)$ & 887 (81.1\%) & 799 (81.6\%) & $<0.00 \mathrm{I}^{\mathrm{a}, \mathrm{b}}$ \\
\hline - Warfarin & $2338(68.7 \%)$ & 795 (59.8\%) & 811 (74.1\%) & 732 (74.8\%) & $<\left.0.00\right|^{a, b}$ \\
\hline - NOACs & 228 (6.7\%) & 85 (6.4\%) & 76 (6.9\%) & 67 (6.8\%) & 0.845 \\
\hline
\end{tabular}

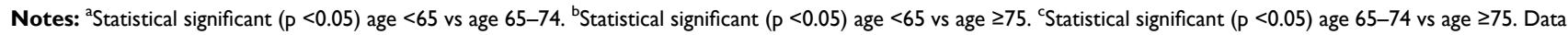
presented as mean \pm standard deviation or number and percentage.

Abbreviations: AF, atrial fibrillation; TIA, transient ischemic attack; NOACs, non-vitamin $\mathrm{K}$ antagonist oral anticoagulants.

A p-value $<0.05$ indicates statistical significance (bold).

adult status to be an independent predictor of the adverse clinical outcomes (Figure 2).

Figure 3 shows the cumulative event rate of ischemic stroke/TIA, major bleeding, ICH, and death over time in patients with age $<65,65-74$, and $\geq 75$ years. The graph shows that age $\geq 75$ years had the highest rate of clinical events as the duration of follow-up became longer.

Sensitivity analysis of the hazard ratios was performed with age used as continuous data, as shown in Figure 4. The risk of adverse outcome increased after the age of 65 years, and markedly increased as the age became more advanced.

\section{Effect of OAC}

OAC reduced the rate of ischemic stroke/TIA in both age groups. The rate of major bleeding in older adult group was higher than in the younger group, especially when they were on OAC. The rate of ICH was more than $1 \%$ per year in patients with age $\geq 75$ years when they were on OAC (Figure 5A). Using NOAC was associated with a lower rate of ischemic stroke/TIA and major bleeding compared to warfarin (Figure 5B). NCB analysis showed benefit of OAC especially high-risk subset (CHA2DS2VASc score $\geq 2$ for male and $\geq 3$ for female) of patients 


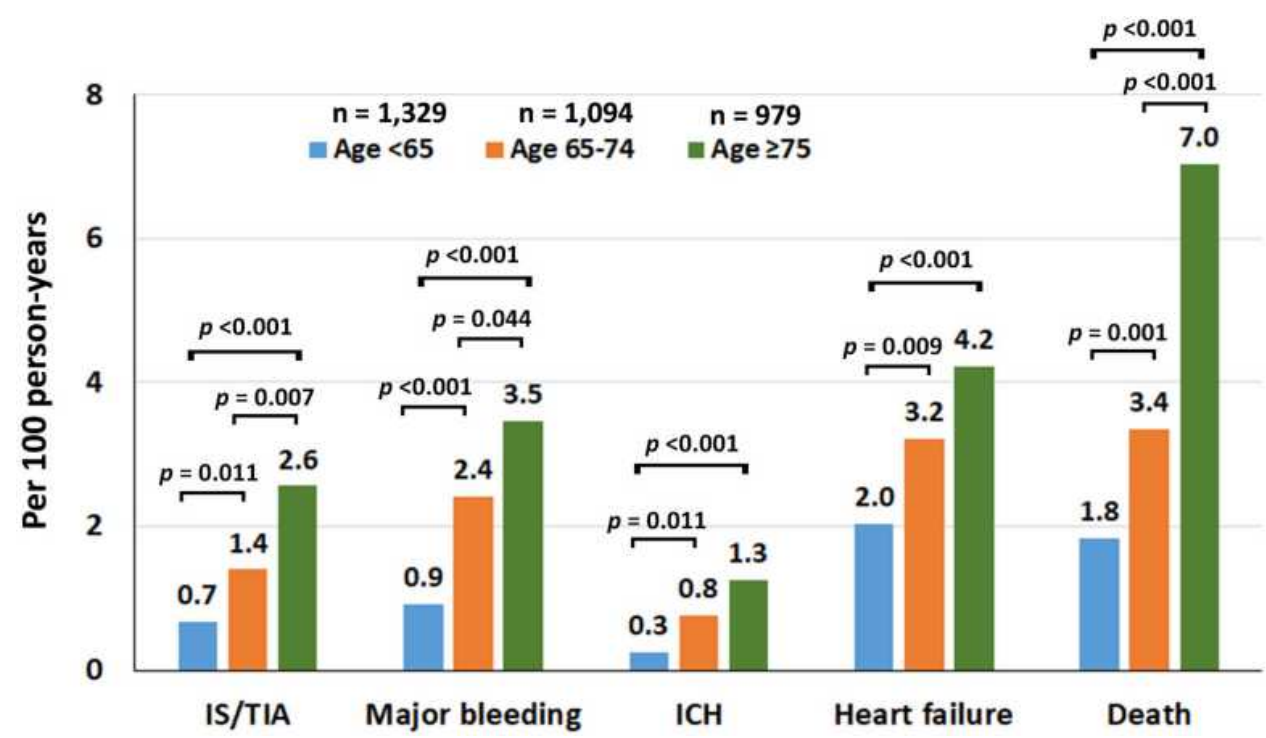

Figure I Incidence rate of ischemic stroke (IS)/transient ischemic attack (TIA), major bleeding (MB), intracerebral hemorrhage (ICH), heart failure (HF), and death compared between patients aged $<65,65-74$, and $\geq 75$ years.

aged 65-74 years, but not in younger adults and those older than 75 years (probably related to the increased risk of $\mathrm{ICH}$ in patients $\geq 75$ years of age) (Figure 5C).
NOAC was associated with a more positive NCB compared to warfarin in both younger and older adults. However, NOAC was used in only 228 patients $(8.9 \%$ of

Table 2 Incidence Rate of Clinical Outcomes According to Age Group

\begin{tabular}{|c|c|c|c|c|}
\hline Age Group & $\begin{array}{l}\text { Number of } \\
\text { Patients }\end{array}$ & $\begin{array}{l}\text { Number of } \\
\text { Events }\end{array}$ & $\begin{array}{l}\text { Follow-Up Time } \\
(\times 100 \text { Person-Years })\end{array}$ & $\begin{array}{c}\text { Incidence Rate per } 100 \text { Person-Years } \\
\qquad(95 \% \mathrm{Cl})\end{array}$ \\
\hline \multicolumn{5}{|c|}{ Ischemic stroke/TIA } \\
\hline Age $<65 y$ & 1329 & 19 & 28.39 & $0.67(0.40-1.04)$ \\
\hline Age $65-74$ y & 1094 & 33 & 23.61 & $1.40(0.96-1.96)$ \\
\hline Age $\geq 75$ y & 979 & 51 & 19.93 & $2.56(1.91-3.37)$ \\
\hline \multicolumn{5}{|c|}{ Major bleeding } \\
\hline Age $<65$ y & 1329 & 26 & 28.39 & $0.92(0.60-1.34)$ \\
\hline Age $65-74$ y & 1094 & 57 & 23.61 & $2.41(1.83-3.13)$ \\
\hline Age $\geq 75 y$ & 979 & 69 & 19.93 & $3.46(2.70-4.39)$ \\
\hline \multicolumn{5}{|c|}{$\mathrm{ICH}$} \\
\hline Age $<65 y$ & 1329 & 7 & 28.39 & $0.25(0.10-0.5 \mathrm{I})$ \\
\hline Age $65-74$ y & 1094 & 18 & 23.61 & $0.76(0.45-1.2 \mathrm{I})$ \\
\hline Age $\geq 75 y$ & 979 & 25 & 19.93 & $1.25(0.81-1.85)$ \\
\hline \multicolumn{5}{|c|}{ Heart failure } \\
\hline Age $<65 y$ & 1329 & 58 & 28.39 & $2.04(1.55-2.64)$ \\
\hline Age $65-74$ y & 1094 & 76 & 23.61 & $3.22(2.54-4.03)$ \\
\hline Age $\geq 75 y$ & 979 & 84 & 19.93 & $4.22(3.37-5.23)$ \\
\hline \multicolumn{5}{|c|}{ Death } \\
\hline Age $<65 y$ & 1329 & 52 & 28.39 & I.83 (I.37-2.40) \\
\hline Age $65-74$ y & 1094 & 79 & 23.61 & $3.35(2.65-4.17)$ \\
\hline Age $\geq 75$ y & 979 & 140 & 19.93 & $7.03(5.92-8.30)$ \\
\hline
\end{tabular}

Abbreviations: $\mathrm{Cl}$, confidence interval; TIA, transient ischemic attack; ICH, intracerebral hemorrhage. 
Table 3 Incidence Rate of Ischemic Stroke/TIA According to Age Group and CHA $\mathrm{DS}_{2}$-VASc Score

\begin{tabular}{|c|c|c|c|c|}
\hline Age Group & $\begin{array}{c}\text { Number of } \\
\text { Patients }\end{array}$ & $\begin{array}{l}\text { Number of } \\
\text { Events }\end{array}$ & $\begin{array}{c}\text { Follow-Up Time } \\
\text { (× } 00 \text { Person-Years) }\end{array}$ & $\begin{array}{c}\text { Incidence Rate per I00 Person- } \\
\text { Years }(95 \% \mathrm{Cl})\end{array}$ \\
\hline \multicolumn{5}{|c|}{ All patients } \\
\hline All & 3402 & 103 & 71.93 & 1.43 \\
\hline $\mathrm{CHA}_{2} \mathrm{DS}_{2}$-VASc 0 & 196 & 3 & 4.04 & 0.74 \\
\hline $\mathrm{CHA}_{2} \mathrm{DS}_{2}$-VASc I & 422 & 5 & 8.90 & 0.56 \\
\hline $\mathrm{CHA}_{2} \mathrm{DS}_{2}-\mathrm{VASc} \geq 2$ & 2784 & 95 & 58.99 & 1.61 \\
\hline \multicolumn{5}{|c|}{ Age $<65$} \\
\hline All & 1329 & 19 & 28.39 & 0.67 \\
\hline $\mathrm{CHA}_{2} \mathrm{DS}_{2}$-VASc 0 & 196 & 3 & 4.04 & 0.74 \\
\hline $\mathrm{CHA}_{2} \mathrm{DS}_{2}$-VASc I & 371 & 4 & 7.83 & 0.51 \\
\hline $\mathrm{CHA}_{2} \mathrm{DS}_{2}-\mathrm{VASc} \geq 2$ & 762 & 12 & 16.52 & 0.73 \\
\hline \multicolumn{5}{|c|}{ Age $65-74$} \\
\hline All & 1094 & 33 & 23.61 & 1.40 \\
\hline $\mathrm{CHA}_{2} \mathrm{DS}_{2}$-VASc 0 & 0 & 0 & 0.00 & - \\
\hline $\mathrm{CHA}_{2} \mathrm{DS}_{2}$-VASc I & 51 & I & 1.07 & 0.94 \\
\hline $\mathrm{CHA}_{2} \mathrm{DS}_{2}-\mathrm{VASc} \geq 2$ & 1043 & 32 & 22.54 & 1.42 \\
\hline \multicolumn{5}{|c|}{ Age $\geq 75$} \\
\hline All & 979 & 51 & 19.93 & 2.56 \\
\hline $\mathrm{CHA}_{2} \mathrm{DS}_{2}$-VASc 0 & 0 & 0 & 0.00 & - \\
\hline $\mathrm{CHA}_{2} \mathrm{DS}_{2}$-VASc I & 0 & 0 & 0.00 & - \\
\hline $\mathrm{CHA}_{2} \mathrm{DS}_{2}-\mathrm{VASc} \geq 2$ & 979 & 51 & 19.93 & 2.56 \\
\hline
\end{tabular}

patients who were on OAC) of our study population. Therefore, no conclusions can be drawn relative to our comparison between OAC and NOAC. The average time in the therapeutic range (TTR) was $53.35 \pm 27.43 \%$. TTR was $53.92 \pm 27.83,54.60 \pm 26.98$, and $51.39 \pm 27.48 \%$ in patients aged $<65,65-74$, and $\geq 75$ years, respectively $(p=0.145)$.

\section{Discussion}

The results of this prospective registry of patients with NVAF demonstrated that adverse clinical outcomes increased with age. Patients with age $\geq 75$ years had at least a 3 times increased risk of ischemic stroke/TIA, major bleeding, $\mathrm{ICH}$, and death, and at least a 2 times increased risk of heart failure. Moreover, the increased risk of older adults for all outcomes remained significant even after adjustment for potential confounders. Although OAC reduced the risk of ischemic stroke/TIA, it increased the risk of major bleeding. $\mathrm{NCB}$ analysis favored OAC in the high-risk subset of older adult population. Although NOAC was used in a small proportion, it had more NCB than warfarin.
Although older adult population with NVAF had an increased risk of ischemic stroke and needed OAC for stroke prevention, a significant proportion of them did not receive OAC. ${ }^{4,18}$ There are many reasons for not using OAC in older adults. The common reasons were fear of bleeding, fear of fall, and the use of antiplatelet. ${ }^{4,12,19}$ The risk of bleeding can be reduced by the use of NOAC agents. Concerning warfarin use, good quality INR control has been associated with better clinical outcomes and a lower risk of bleeding. ${ }^{20}$ Previous data from the GARFIELD AF registry showed that the quality of INR control in 3621 Asian patients was poorer than in 13,541 patients from other regions of the world. ${ }^{13}$ Guideline defines good INR control as a having a TTR of $70 \%$ or more. ${ }^{2}$ However, the majority of Asians and non-Asians on warfarin did not reach the target TTR. ${ }^{13}$ Fear of fall is a common reason for not using OAC. However, a previous study reported that patients taking warfarin must fall at least 295 times in 1 year for the bleeding risk of warfarin outweighs the benefit. ${ }^{21}$ Using antiplatelet should not be a reason for not using OAC. Antiplatelet alone cannot protect NVAF patients from 


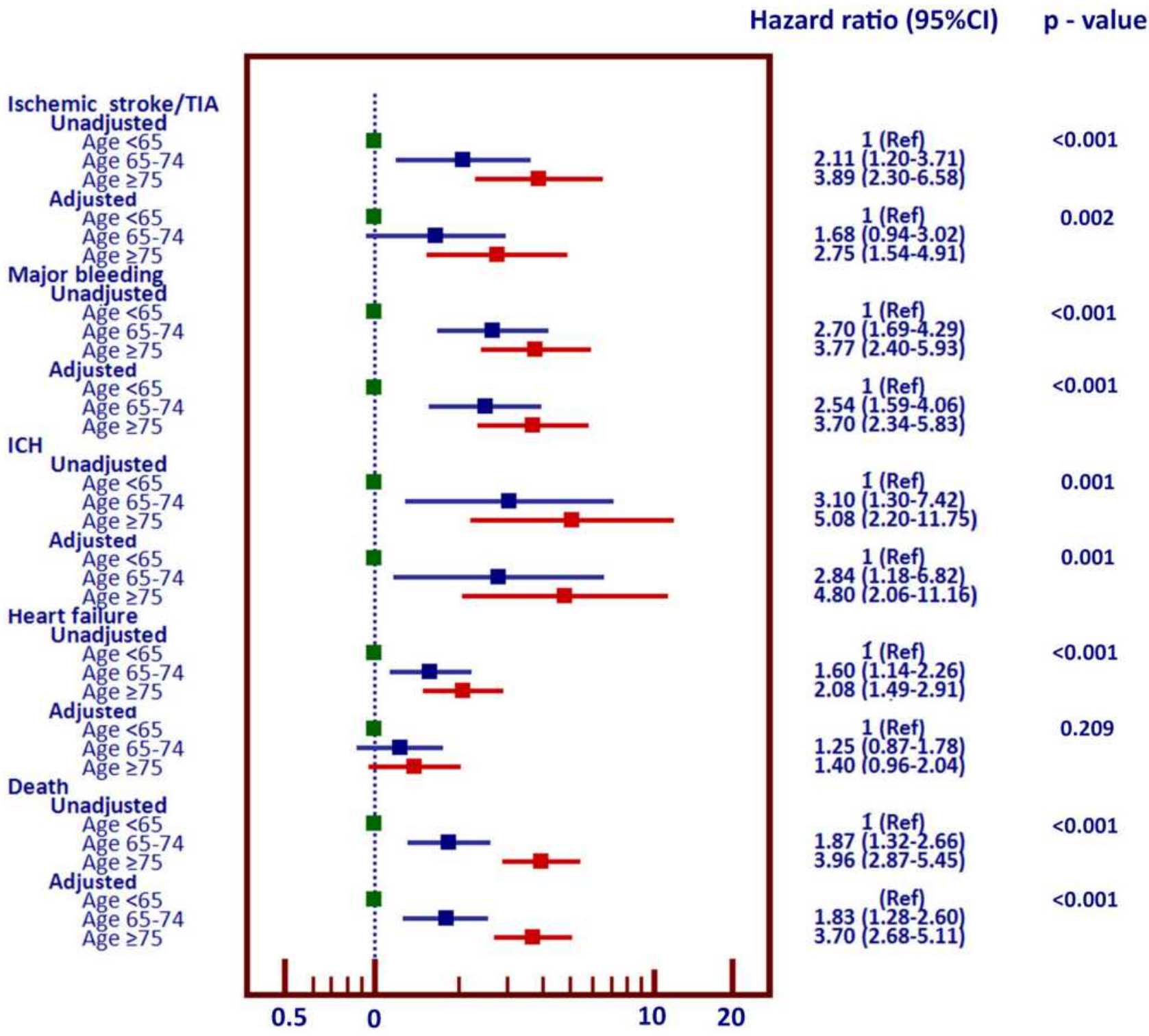

Figure 2 Forest plot of unadjusted and adjusted hazard ratios and their $95 \%$ confidence intervals for ischemic stroke/transient ischemic attack (TIA), major bleeding, intracerebral hemorrhage $(\mathrm{ICH})$, heart failure, and death in patients aged $65-74$, and $\geq 75$ years as compared to those aged $<65$ years $(<65$ years was used as a reference).

ischemic stroke. ${ }^{22}$ Guidelines recommended against the use of antiplatelet for stroke prevention in NVAF. $2,23,24$ The use of antiplatelet in combination with $\mathrm{OAC}$ in patients with stable CAD has no additional benefit for stroke prevention, but significantly increased bleeding risk. $^{25,26}$

Our study showed that older adults have an increased risk of ischemic stroke/TIA, major bleeding including $\mathrm{ICH}$, heart failure, and death. The increased risk persisted despite controlling for risk factors and comorbid conditions. Although it is known that elderly group had an increased risk of clinical event, we also reported the magnitude of the increased risk and we also compared incidence rate of clinical outcomes of three age groups ( $<65,65-74$, and $\geq 75$ years). Our finding on the risk of stroke confirmed results from previous studies in Asians ${ }^{27}$ and non-Asians ${ }^{28}$ that elderly status is an independent risk factor for ischemic stroke in NVAF. The age-related risk of ischemic stroke persisted even at age greater than 90 years in both Asians ${ }^{29}$ and Western ${ }^{30}$ population. The increased risk of bleeding, including $\mathrm{ICH}$, also significantly increased with age - even at an age above 90 years. ${ }^{30}$ A previous study reported the reason for increased risk of bleeding to be poorer INR control. ${ }^{30}$ However, the TTR in our study was not different between different age groups, so this could not explain the increased risk of bleeding. 
Unadjusted

A

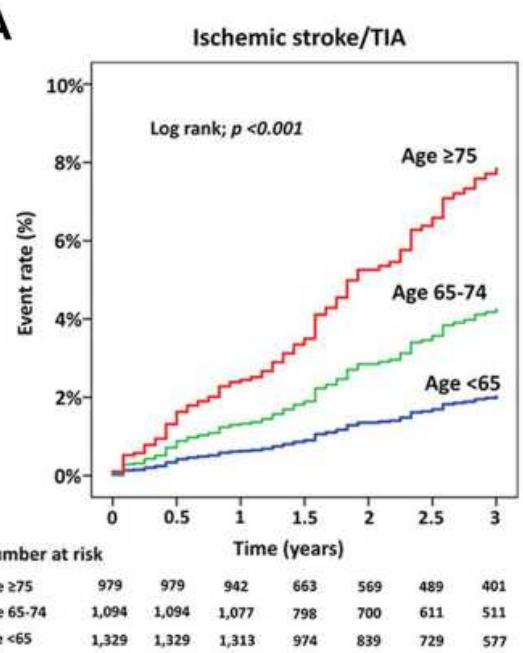

B

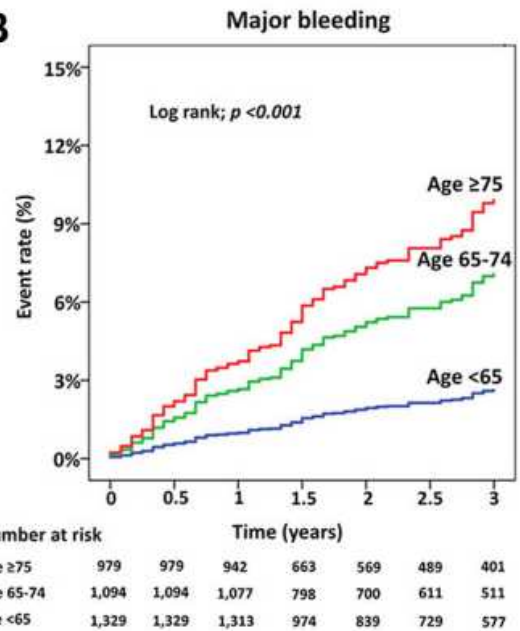

C

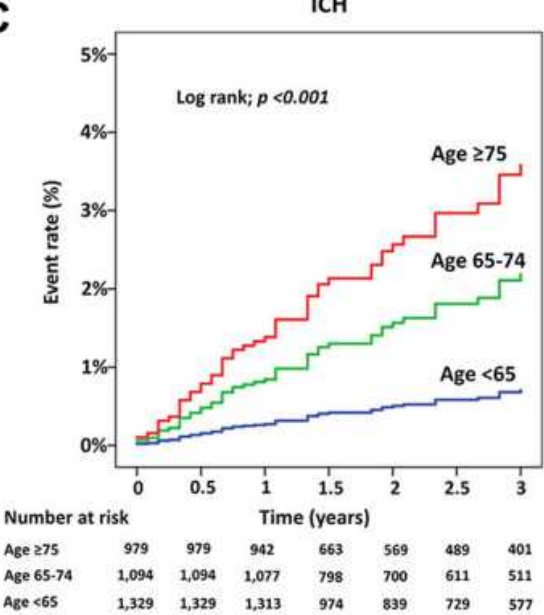

Adjusted

D

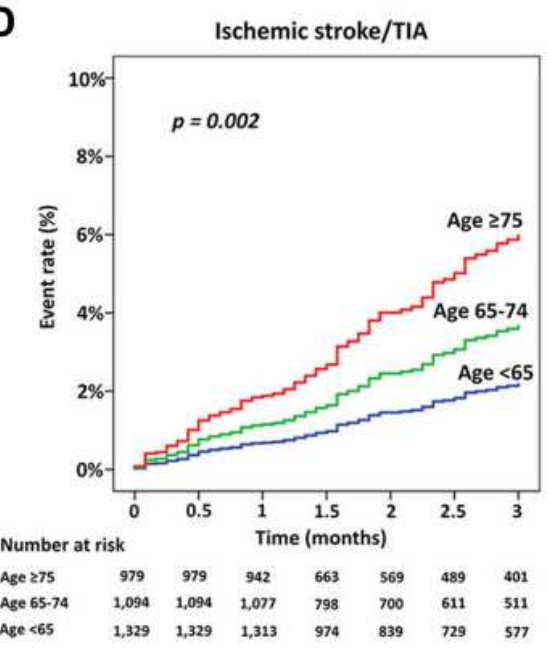

E

Major bleeding

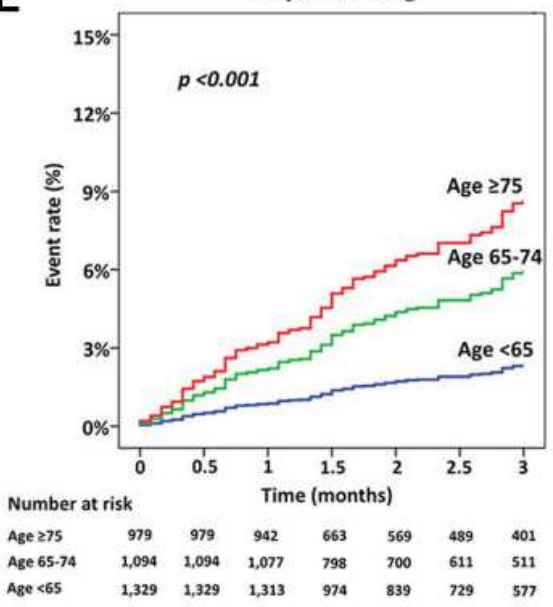

F

ICH

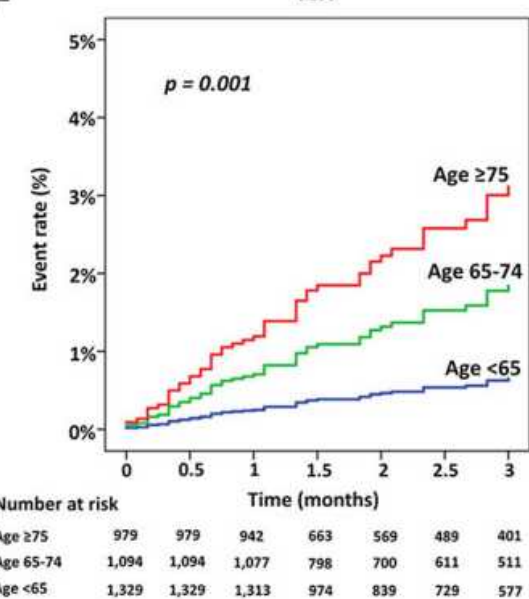

Figure 3 Cumulative event rate for ischemic stroke/transient ischemic attack (TIA), major bleeding, intracerebral hemorrhage (ICH), and death over time compared between patients aged $<65,65-74$, and $\geq 75$ years. A-C: unadjusted analysis. D-F: analysis adjusted for confounders. 

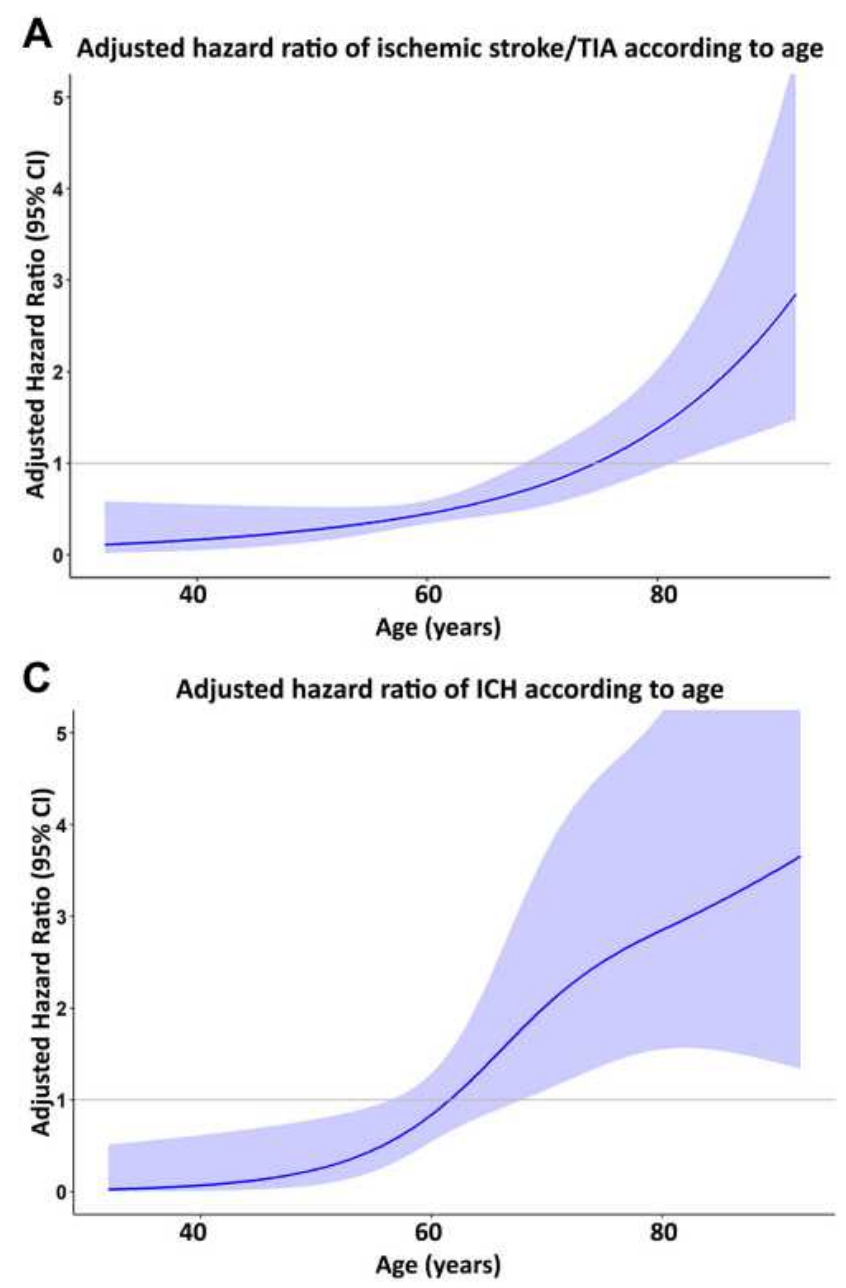

B Adjusted hazard ratio of major bleeding according to age

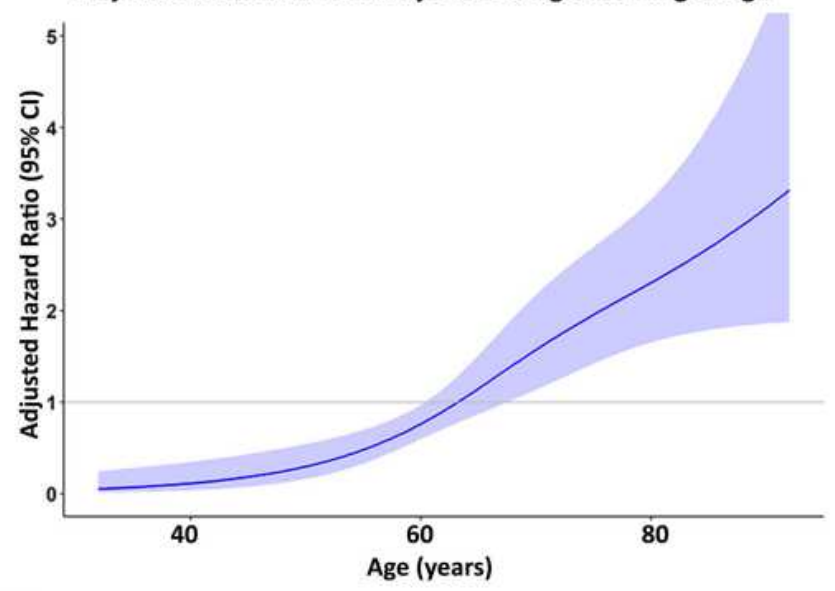

D Adjusted hazard ratio of death according to age

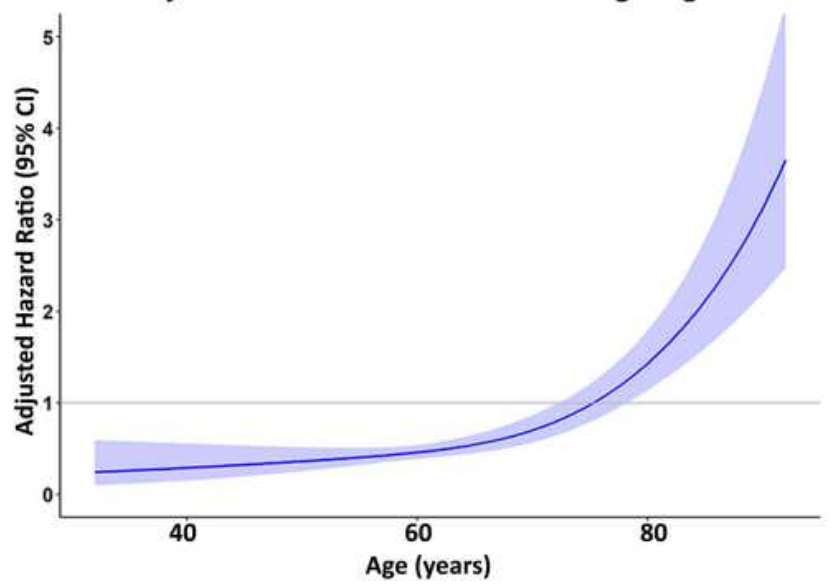

Figure 4 Cubic spline graph of adjusted hazard ratio (blue line) and $95 \%$ confidence interval (purple shaded area) (Y-axis) relative to age (X-axis) for (A) ischemic stroke/ transient ischemic attack (TIA), (B) major bleeding, (C) intracerebral hemorrhage (ICH), and (D) death.

Moreover, the rate of major bleeding in our study was high compared to previous data, which is mainly from Western population. $^{31}$ The incidence rate of major bleeding in our study was 2.11 per 100 person-years compared to 0.7 per 100 person-years from the GARFIELD AF registry. ${ }^{31}$ Increased risk of major bleeding, including $\mathrm{ICH}$, was previously reported, ${ }^{32}$ and is consistent with data from four large NOAC clinical trials. ${ }^{11}$ Results from the Fushimi study confirmed the increased risk of major bleeding in Asian population as evidenced by the incidence rate of major bleeding of 1.64 and 2.08 per 100 person-years in females and males, respectively. ${ }^{33}$ Data from Taiwanese population from the Taiwan national health insurance database also confirmed the increased risk of major bleeding in Asians with an incidence rate of 2-3 per 100 person-years among different OACs. ${ }^{34}$

Although the guidelines recommended the use of OAC in older adult population, the results of NCB analysis in our study indicated that OAC had no significant benefit relative to balancing ischemic stroke and bleeding risk. OAC tended to have benefits in the older adult group, but not in the younger adult group. Use of NOAC had significant $\mathrm{NCB}$ over warfarin both in older and younger adults. However, the rate of NOAC use in our study was relatively small compared to $\mathrm{OAC}$, so we are unable to draw any conclusions from that aspect of our analysis. However, our finding supports the previously reported benefit of NOAC use in elderly population ${ }^{5}$ - even in patients aged more than 90 years. ${ }^{29}$ NOACs are the preferred choice mainly due to the lower risk of $\mathrm{ICH}^{11}$

NVAF not only increased the risk of ischemic stroke and major bleeding but it also increased the risk of heart failure and death. The incidence rate of heart failure and death in our study was 3.03 and 3.77 per 100 personyears, respectively. The rate of heart failure was even higher than the rate of ischemic stroke and major 
A

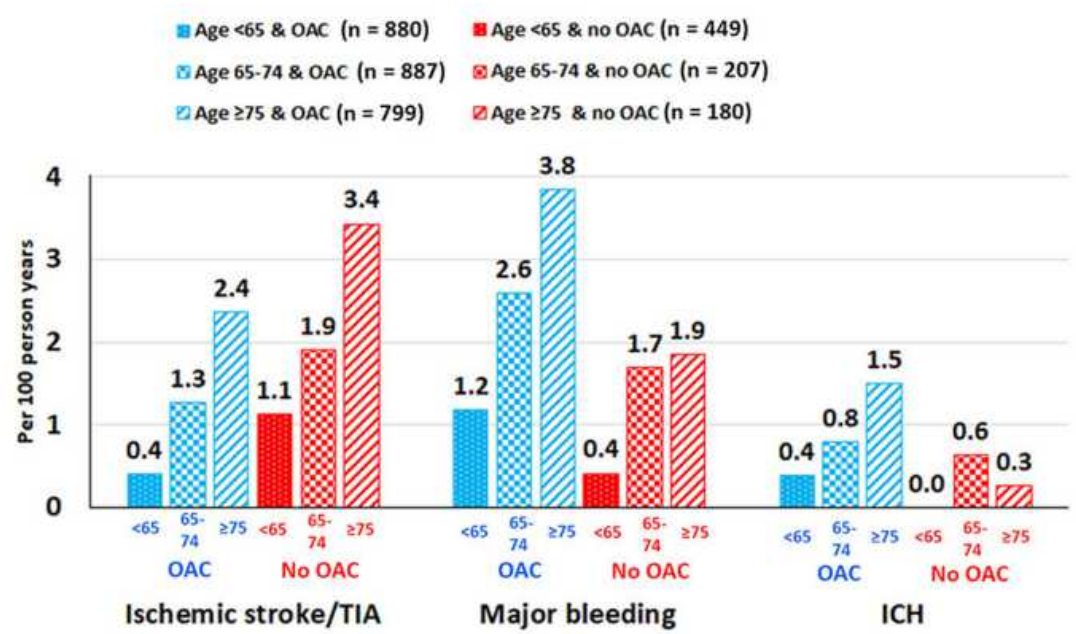

B
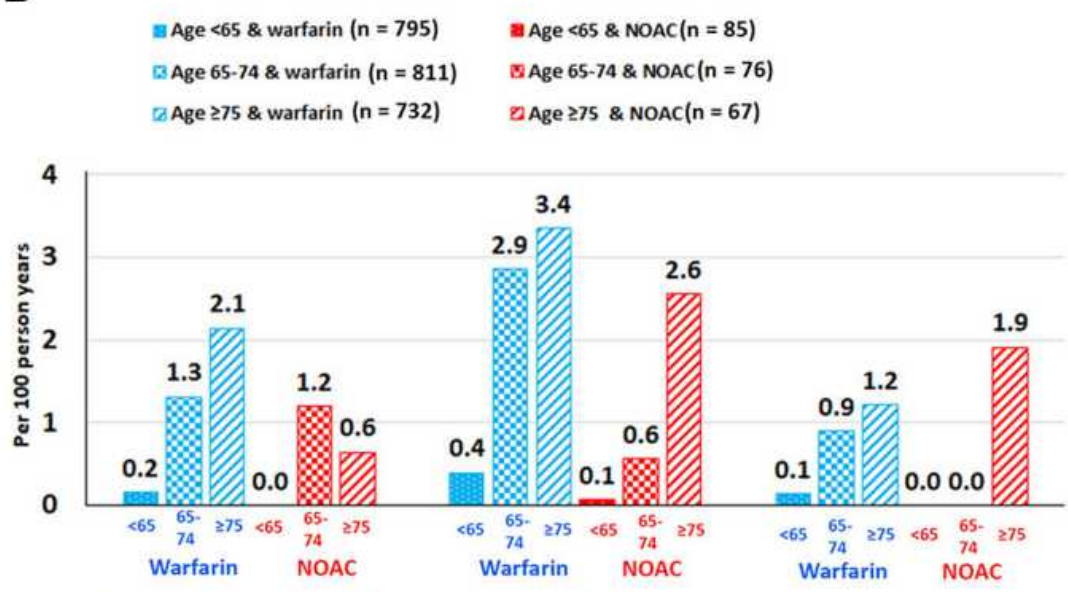

Ischemic stroke/TIA Major bleeding ICH

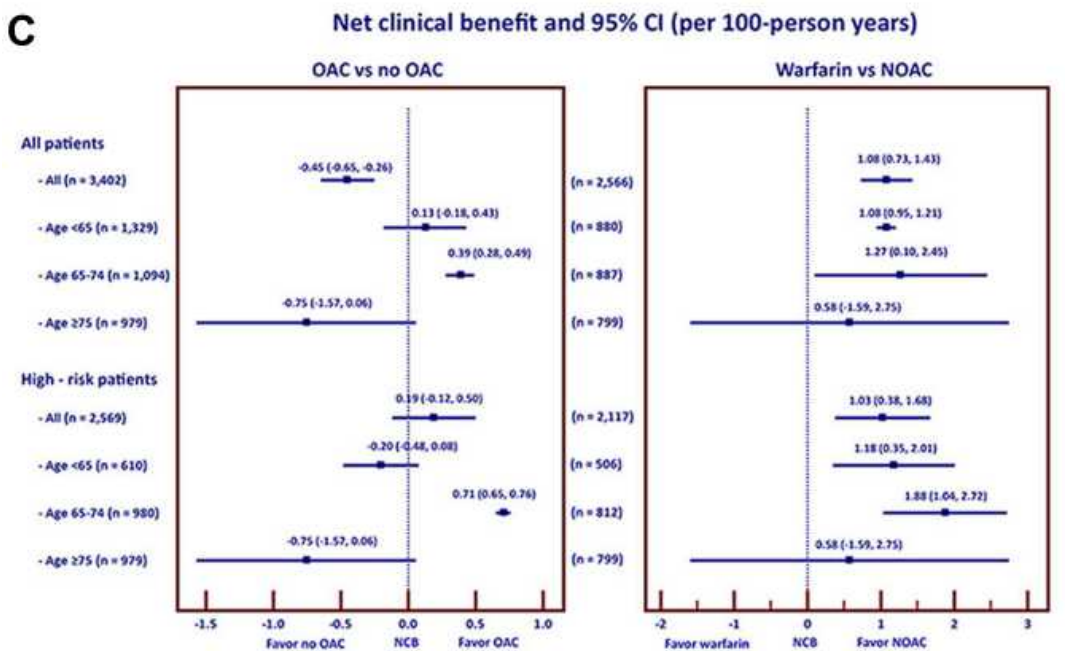

Figure 5 Rate of ischemic stroke (IS)/transient ischemic attack (TIA), major bleeding, and intracerebral hemorrhage (ICH) according to age and oral anticoagulant (OAC) status (A), and according to age compared between warfarin and non-vitamin K antagonist oral anticoagulant (NOAC) (B). Net clinical benefit (NCB) and $95 \%$ confidence interval $(\mathrm{Cl})$ according to age compared between OAC and no OAC, and between NOAC and warfarin (C). 
bleeding. The rate of heart failure in our study was higher than that from the GARFIELD AF registry, ${ }^{31}$ and comparable to the results of the FUSHIMI study. ${ }^{33}$ NVAF can lead to heart failure and vice versa. ${ }^{35}$ Recent data showed that integrated care, ${ }^{36}$ such as $\mathrm{ABC}$ pathway $(\mathrm{A}=$ Avoid stroke with anticoagulation, $\mathrm{B}=$ better symptom management, and $\mathrm{C}=$ Cardiovascular and comorbidity risk management), should be encouraged to reduce the cardiovascular risk of patients with NVAF. ${ }^{37}$ Due to the increased risk of clinical outcomes with increasing age, many treatment and preventative strategies should be mentioned. Appropriate use of OAC should be emphasized. Inappropriate use of antiplatelets should be avoided to minimize the risk of ischemic stroke/TIA. NOACs are the preferred choice to minimize the bleeding risk. Whenever, warfarin are used, INR should be monitored closely and TTR should be more than $70 \%$ if possible. Early detection and treatment of comorbid conditions such as hypertension and diabetes and other complications such as heart failure should be managed in the timely manner. ${ }^{38}$

This study has some limitations. First, his study mainly included patients who received their care at a large medical center. This suggests the possibility that our results may not apply to patients that receive their care at a smaller and perhaps less sophisticated center. Second, although investigators were informed to enroll consecutive cases, there might be the possibility of selection bias. Third, the proportion of patients that used NOAC was small. This is related to the government policy to limit the use of the expensive drug and ask physicians to start OAC with warfarin and physicians had to indicate the reasons for using NOACs in the drug utilization evaluation (DUE) form. Since the number of patients who used NOACs were small and patients in warfarin group had a suboptimal TTR, we cannot make conclusion for results of comparison of clinical outcomes between NOACs and warfarin. Fourth, patients with $\mathrm{AF}$ from transient cause were excluded. Although there have been studies indicating that even patients with $\mathrm{AF}$ from transient cause had an increased risk of ischemic stroke, ${ }^{39}$ the benefit of OAC in this situation remained uncertain. ${ }^{40}$ Therefore, we did not include this group. We defined as the first episode of transient AF usually during obvious situation such as pneumonia or sepsis. We should also mention the strengths of this study. First, this was a multicenter nationwide study that included 27 centers located all across Thailand. Second, this study had a prospective data collection design with a well-planned and audited data collection scheme. Third, we performed site monitoring at every study site to ensure data quality. Lastly, all primary outcome events were adjudicated.

\section{Conclusion}

The risk of ischemic stroke/TIA, major bleeding, intracranial hemorrhage, heart failure, and death in patients with NVAF increased with age despite the adjustment for potential confounders. Strategies to reduce overall risk, including use and choice of $\mathrm{OAC}$ and integrated care, should be implemented.

\section{Data Sharing Statement}

The dataset that was used to support the results and conclusion of this study are included within the manuscript. The additional data are available from corresponding author upon reasonable request.

\section{Ethical Approval and Consent to Participate}

This study was approved by the Institutional Review Board of the Central Research Ethics Committee (CREC) (COA-CREC003/2014), and all patients provided written informed consent prior to participation. All study protocol procedures were carried out in accordance with the Helsinki Declaration.

\section{Acknowledgments}

The authors gratefully acknowledge Chulalak Komoltri, $\mathrm{PhD}$, for statistical analysis and Pontawee Kaewkumdee, BNS, study coordination and Ahthit Yindeengam, BSc, and data management. List of COOL-AF investigators: Buddhachinaraj Hospital: Tomorn Thongsri, MD; Central Chest Institute of Thailand: Kriengkrai Hengrussamee, MD; Charoen Krung Pracha Rak Hospital: Pattraporn Srirattana, MD; Chiangrai Prachanukroh Hospital: Wattana Wongtheptien, MD; Chonburi Hospital Pornchai Ngamjanyaporn, MD; Faculty of Medicine, Chiang Mai University: Arintaya Phrommintikul, MD; Faculty of Medicine, Chulalongkorn University: Smonporn Boonyaratavej, MD; Faculty of Medicine, Naresuan University: Pongpun Jittham, MD; Faculty of Medicine, Prince of Songkla University: Treechada Wisartpong, MD; Faculty of Medicine Ramathibodi Hospital, Mahidol University: Sirin Apiyasawat, MD; Faculty of Medicine Siriraj Hospital, Mahidol 
University: Arjbordin Winijkul, MD and Rungroj Krittayaphong, MD; Faculty of Medicine, Thammasat University (Rangsit Campus): Roj Rojretamphai, MD; Faculty of Medicine Vajira Hospital, Navamindradhiraj University: Kulyot Jongpiputvanich, MD; Golden Jubilee Medical Center: Somchai Dutsadeevettakul, MD; Khon Kaen Hospital: Chaisit Wongwipaporn, MD; Lampang Hospital: Tanita Bunyapipat, MD; Maharat Nakorn Ratchasima Hospital: Weerapan Wiwatworapan, MD; Nakornping Hospital: Khanchai Siriwattana, MD; Phramongkutklao College of Medicine: Tharanit Chantrarat, MD; Police General Hospital: Kasem Rattanasumawong, MD; Prapokklao Hospital (Chanthaburi): Wiwat Kanjanarutjawiwat, MD; Queen Savang Vadhana Memorial Hospital: Sakaorat Kornbongkotmas; MD; Ratchaburi Hospital: Thanasak Patmuk, MD; Sapphasitthiprasong Hospital: Praprut Thanakitcharu, MD; Surat Thani Hospital: Suchart Arunsiriwattana, MD; Surin Hospital: Thaworn Choochunklin; MD; Udon Thani Hospital: Sumon Tangsuntornwiwat, MD.

\section{Author Contributions}

All authors made substantial contributions to conception and design, acquisition of data, or analysis and interpretation of data; took part in drafting the article or revising it critically for important intellectual content; agreed to submit to the current journal; gave final approval of the version to be published; and agree to be accountable for all aspects of the work.

\section{Funding}

This study was funded by grants from the Health Systems Research Institute (HSRI) (grant no. 59-053), and the Heart Association of Thailand under the Royal Patronage of H.M. the King. None of the aforementioned funding sources influenced any aspect of this study or the decision of the authors to submit this manuscript for publication.

\section{Disclosure}

All authors declare no conflicts of interest for this work and no financial support from the companies that produce and/or distribute the drugs, devices, or materials described in this report.

\section{References}

1. Tse HF, Wang YJ, Ahmed Ai-Abdullah M, et al. Stroke prevention in atrial fibrillation-an Asian stroke perspective. Heart Rhythm. 2013;10 (7):1082-1088. doi:10.1016/j.hrthm.2013.03.017
2. Kirchhof P, Benussi S, Kotecha D, et al. 2016 ESC Guidelines for the management of atrial fibrillation developed in collaboration with EACTS. Eur Heart J. 2016;37(38):2893-2962.

3. Lip GY, Nieuwlaat R, Pisters R, Lane DA, Crijns HJ. Refining clinical risk stratification for predicting stroke and thromboembolism in atrial fibrillation using a novel risk factor-based approach: the euro heart survey on atrial fibrillation. Chest. 2010;137(2):263-272. doi:10.1378/chest.09-1584

4. Krittayaphong R, Phrommintikul A, Ngamjanyaporn P, et al. Rate of anticoagulant use, and factors associated with not prescribing anticoagulant in older Thai adults with non-valvular atrial fibrillation: a multicenter registry. J Geriatr Cardiol. 2019;16(3):242-250. doi:10.11909/j.issn.1671-5411.2019.03.004

5. Ng KH, Hart RG, Eikelboom JW. Anticoagulation in patients aged $>/=75$ years with atrial fibrillation: role of novel oral anticoagulants. Cardiol Ther. 2013;2(2):135-149. doi:10.1007/s40119-013-0019-y

6. Karamichalakis N, Letsas KP, Vlachos K, et al. Managing atrial fibrillation in the very elderly patient: challenges and solutions. Vasc Health Risk Manag. 2015;11:555-562. doi:10.2147/VHRM.S83664

7. Pisters R, Lane DA, Nieuwlaat R, de Vos CB, Crijns HJ, Lip GY. A novel user-friendly score (HAS-BLED) to assess 1-year risk of major bleeding in patients with atrial fibrillation: the Euro Heart Survey. Chest. 2010;138(5):1093-1100. doi:10.1378/chest.10-0134

8. Poli D, Antonucci E, Testa S, et al. Bleeding risk in very old patients on vitamin $\mathrm{K}$ antagonist treatment: results of a prospective collaborative study on elderly patients followed by Italian Centres for Anticoagulation. Circulation. 2011;124(7):824-829. doi:10.1161/ CIRCULATIONAHA.110.007864

9. Fang MC, Go AS, Hylek EM, et al. Age and the risk of warfarin-associated hemorrhage: the anticoagulation and risk factors in atrial fibrillation study. $J$ Am Geriatr Soc. 2006;54(8):1231-1236. doi:10.1111/j.1532-5415.2006.00828.x

10. Lip GY, Wang KL, Chiang CE. Non-vitamin K antagonist oral anticoagulants (NOACs) for stroke prevention in Asian patients with atrial fibrillation: time for a reappraisal. Int J Cardiol. 2015;180:246-254. doi:10.1016/j.ijcard.2014.11.182

11. Chiang CE, Wang KL, Lip GY. Stroke prevention in atrial fibrillation: an Asian perspective. Thromb Haemost. 2014;111(5):789-797. doi:10.1160/TH13-11-0948

12. Donze J, Clair C, Hug B, et al. Risk of falls and major bleeds in patients on oral anticoagulation therapy. Am J Med. 2012;125 (8):773-778. doi:10.1016/j.amjmed.2012.01.033

13. Oh S, Goto S, Accetta G, et al. Vitamin $\mathrm{K}$ antagonist control in patients with atrial fibrillation in Asia compared with other regions of the world: real-world data from the GARFIELD-AF registry. Int J Cardiol. 2016;223:543-547. doi:10.1016/j.ijcard.2016.08.236

14. Aribou ZM, Mondry A. Anticoagulation needs in Asians with atrial fibrillation: a mythbuster. Ann Acad Med Singapore. 2014;43 (5):275-278.

15. Krittayaphong R, Winijkul A, Methavigul K, et al. Risk profiles and pattern of antithrombotic use in patients with non-valvular atrial fibrillation in Thailand: a multicenter study. BMC Cardiovasc Disord. 2018;18(1):174. doi:10.1186/s12872-018-0911-4

16. Schulman S, Kearon C; Subcommittee on Control of Anticoagulation of the Scientific and Standardization Committee of the International Society on Thrombosis and Haemostasis. Definition of major bleeding in clinical investigations of antihemostatic medicinal products in non-surgical patients. J Thromb Haemost. 2005;3(4):692-694. doi:10.1111/j.1538-7836.2005.01204.x

17. Singer DE, Chang Y, Fang MC, et al. The net clinical benefit of warfarin anticoagulation in atrial fibrillation. Ann Intern Med. 2009;151 (5):297-305. doi:10.7326/0003-4819-151-5-200909010-00003

18. Gao Q, Fu X, Wei JW, et al. Use of oral anticoagulation among stroke patients with atrial fibrillation in China: the ChinaQUEST (Quality evaluation of stroke care and treatment) registry study. Int $J$ Stroke. 2013;8(3):150-154. doi:10.1111/j.1747-4949.2011.00716.x 
19. Kakkar AK, Mueller I, Bassand JP, et al. Risk profiles and antithrombotic treatment of patients newly diagnosed with atrial fibrillation at risk of stroke: perspectives from the international, observational, prospective GARFIELD registry. PLoS One. 2013;8(5):e63479. doi:10.1371/journal.pone.0063479

20. Haas S, Ten Cate H, Accetta G, et al. Quality of vitamin K antagonist control and 1-year outcomes in patients with atrial fibrillation: a global perspective from the GARFIELD-AF registry. PLoS One. 2016;11(10):e0164076. doi:10.1371/journal.pone.0164076

21. Man-Son-Hing M, Nichol G, Lau A, Laupacis A. Choosing antithrombotic therapy for elderly patients with atrial fibrillation who are at risk for falls. Arch Intern Med. 1999;159(7):677-685. doi:10.1001/ archinte.159.7.677

22. Sato H, Ishikawa K, Kitabatake A, et al. Low-dose aspirin for prevention of stroke in low-risk patients with atrial fibrillation: Japan Atrial Fibrillation Stroke Trial. Stroke. 2006;37(2):447-451. doi:10.1161/01.STR.0000198839.61112.ee

23. January CT, Wann LS, Calkins H, et al. 2019 AHA/ACC/HRS focused update of the 2014 AHA/ACC/HRS guideline for the management of patients with atrial fibrillation: a report of the American College of Cardiology/American Heart Association Task Force on Clinical Practice Guidelines and the Heart Rhythm Society. $J$ Am Coll Cardiol. 2019;74(1):104-132. doi:10.1016/j.jacc.2019.01.011

24. Lip GYH, Banerjee A, Boriani G, et al. Antithrombotic therapy for atrial fibrillation: CHEST guideline and expert panel report. Chest. 2018;154(5):1121-1201.

25. Patti G, Pecen L, Lucerna M, et al. Outcomes of anticoagulated patients with atrial fibrillation treated with or without antiplatelet therapy - A pooled analysis from the PREFER in AF and PREFER in AF PROLONGATON registries. Int J Cardiol. 2018;270:160-166. doi:10.1016/j.ijcard.2018.06.098

26. Sindet-Pedersen C, Lamberts M, Staerk L, et al. Combining oral anticoagulants with platelet inhibitors in patients with atrial fibrillation and coronary disease. J Am Coll Cardiol. 2018;72 (15):1790-1800. doi:10.1016/j.jacc.2018.07.054

27. Yamashita Y, Hamatani Y, Esato M, et al. Clinical characteristics and outcomes in extreme elderly (age $>/=85$ years) Japanese patients with atrial fibrillation: the Fushimi AF registry. Chest. 2016;149 (2):401-412. doi:10.1378/chest.15-1095

28. Senoo K, An Y, Ogawa H, et al. Stroke and death in elderly patients with atrial fibrillation in Japan compared with the United Kingdom. Heart. 2016;102(23):1878-1882. doi:10.1136/heartjnl-2016-309741

29. Chao TF, Liu CJ, Lin YJ, et al. Oral anticoagulation in very elderly patients with atrial fibrillation: a Nationwide Cohort Study. Circulation. 2018;138(1):37-47. doi:10.1161/CIRCULATIONAH A. 117.031658
30. Kooistra HA, Calf AH, Piersma-Wichers M, et al. Risk of bleeding and thrombosis in patients 70 years or older using vitamin $\mathrm{K}$ antagonists. JAMA Intern Med. 2016;176(8):1176-1183. doi:10.1001/jamainternmed.2016.3057

31. Bassand JP, Accetta G, Camm AJ, et al. Two-year outcomes of patients with newly diagnosed atrial fibrillation: results from GARFIELD-AF. Eur Heart J. 2016;37(38):2882-2889. doi:10.1093/ eurheartj/ehw233

32. Shen AY, Yao JF, Brar SS, Jorgensen MB, Chen W. Racial/ethnic differences in the risk of intracranial hemorrhage among patients with atrial fibrillation. $J \mathrm{Am}$ Coll Cardiol. 2007;50(4):309-315. doi:10.1016/j.jacc.2007.01.098

33. Ogawa H, Hamatani Y, Doi K, et al. Sex-related differences in the clinical events of patients with atrial fibrillation- the Fushimi AF registry. Circulation J. 2017;81(10):1403-1410. doi:10.1253/circj. CJ-17-0071

34. Chan YH, See LC, Tu HT, et al. Efficacy and safety of apixaban, dabigatran, rivaroxaban, and warfarin in Asians with nonvalvular atrial fibrillation. $J$ Am Heart Assoc. 2018;7(8). doi:10.1161/ JAHA.117.008150.

35. Kotecha D, Piccini JP. Atrial fibrillation in heart failure: what should we do? Eur Heart J. 2015;36(46):3250-3257. doi:10.1093/eurheartj/ ehv513

36. van den Dries CJ, van Doorn S, Rutten FH, et al. Integrated management of atrial fibrillation in primary care: results of the ALL-IN cluster randomized trial. Eur Heart J. 2020;41(30):2836-2844. doi:10.1093/eurheartj/ehaa055

37. Pastori D, Pignatelli P, Menichelli D, Violi F, Lip GYH. Integrated care management of patients with atrial fibrillation and risk of cardiovascular events: the ABC (Atrial fibrillation Better Care) pathway in the ATHERO-AF Study Cohort. Mayo Clin Proc. 2019;94 (7):1261-1267. doi:10.1016/j.mayocp.2018.10.022

38. Hindricks G, Potpara T, Dagres N, et al. 2020 ESC Guidelines for the diagnosis and management of atrial fibrillation developed in collaboration with the European Association of Cardio-Thoracic Surgery (EACTS). Eur Heart J. 2020.

39. Walkey AJ, Hammill BG, Curtis LH, Benjamin EJ. Long-term outcomes following development of new-onset atrial fibrillation during sepsis. Chest. 2014;146(5):1187-1195. doi:10.1378/chest.14-0003

40. Quon MJ, Behlouli H, Pilote L. Anticoagulant use and risk of ischemic stroke and bleeding in patients with secondary atrial fibrillation associated with acute coronary syndromes, acute pulmonary disease, or sepsis. JACC Clin Electrophysiol. 2018;4(3):386-393. doi:10.1016/j.jacep.2017.08.003
Clinical Interventions in Aging

\section{Publish your work in this journal}

Clinical Interventions in Aging is an international, peer-reviewed journal focusing on evidence-based reports on the value or lack thereof of treatments intended to prevent or delay the onset of maladaptive correlates of aging in human beings. This journal is indexed on PubMed Central, MedLine, CAS, Scopus and the Elsevier
Bibliographic databases. The manuscript management system is completely online and includes a very quick and fair peer-review system, which is all easy to use. Visit http://www.dovepress.com/ testimonials.php to read real quotes from published authors. 